\title{
Multidrug resistant and extensively drug resistant Acinetobacter baumannii hospital infection associated with high mortality: a retrospective study in the pediatric intensive care unit
}

Jingyi Shi ${ }^{1+}$, Ting Sun ${ }^{1 \dagger}$, Yun Cui ${ }^{1}$, Chunxia Wang ${ }^{1,2}$, Fei Wang ${ }^{1}$, Yiping Zhou ${ }^{1}$, Huijie Miao ${ }^{1}$, Yijun Shan ${ }^{1}$ and Yucai Zhang ${ }^{1,2,3^{*}}$ (D)

\begin{abstract}
Background: Multidrug resistant (MDR) and extensively drug resistant (XDR) Acinetobacter baumannii presents challenges for clinical treatment and causes high mortality in children. We aimed to assess the risk factors and overall mortality for MDR/XDR Acinetobacter baumannii infected pediatric patients.
\end{abstract}

Methods: This retrospective study included 102 pediatric patients who developed MDR/XDR Acinetobacter baumannii infection in the pediatric intensive care unit (PICU) of Shanghai Children's Hospital in China from December 2014 to May 2018.

Acinetobacter baumannii clinical isolates were recovered from different specimens including blood, sputum, bronchoalveolar lavage fluid, cerebrospinal fluid, ascites, hydrothorax, and urine. Antibiotic susceptibility test was determined according to the Clinical and Laboratory Standards Institute interpretive criteria. Clinical and biological data were obtained from the patients' medical records.

\footnotetext{
* Correspondence: zyucai2018@163.com

†Jingyi Shi and Ting Sun contributed equally to this work.

'Department of Critical Care Medicine, Shanghai Children's Hospital,

Shanghai Jiao Tong University, Shanghai 20062, China

${ }^{2}$ Institute of Pediatric Critical Care, Shanghai Jiao Tong University, Shanghai

20062, China

Full list of author information is available at the end of the article
}

C C The Author(s). 2020 Open Access This article is licensed under a Creative Commons Attribution 4.0 International License, which permits use, sharing, adaptation, distribution and reproduction in any medium or format, as long as you give appropriate credit to the original author(s) and the source, provide a link to the Creative Commons licence, and indicate if changes were made. The images or other third party material in this article are included in the article's Creative Commons licence, unless indicated otherwise in a credit line to the material. If material is not included in the article's Creative Commons licence and your intended use is not permitted by statutory regulation or exceeds the permitted use, you will need to obtain permission directly from the copyright holder. To view a copy of this licence, visit http://creativecommons.org/licenses/by/4.0/. The Creative Commons Public Domain Dedication waiver (http://creativecommons.org/publicdomain/zero/1.0/) applies to the data made available in this article, unless otherwise stated in a credit line to the data. 


\begin{abstract}
(Continued from previous page)
Results: 102 patients with Acinetobacter baumannii infection were enrolled. The median age was $36(9.6,98.8)$ months, and there were 63 male in the case group. The overall mortality rate was $29.4 \%$, while the Acinetobacter baumannii-associated mortality rate was 16.7\% (17/102, 12 bloodstream infections, 4 meningitis and 1 intra-abdominal infection). Bloodstream infections occurred in 28 patients (27.5\%), and 10 patients (9.8\%) among them had central lineassociated bloodstream infections (6 central venous catheters, 2 PICCS, 1 venous infusion port and 1 arterial catheter). Cerebrospinal fluid (CSF) cultures were positive in 4(3.9\%) patients. 14(13.7\%) patients got positive cultures in ascites and hydrothorax. Lower respiratory isolates (56/102) accounted for $54.9 \%$ of all patients. Non-survival patients appeared to have a lower NK cell activity $(6.2 \% \pm 3.61 \%$ vs. $9.15 \% \pm 6.21 \%, P=0.029)$, higher CD4+ T cell ratio $(39.67 \% \pm 12.18 \%$ vs. $32.66 \% \pm 11.44 \%, P=0.039)$,and a higher serum level of interlukin-8 (IL-8, $15.25(1.62,47.22) \mathrm{gg} / \mathrm{mL}$ vs. $0.1(0.1$, 22.99) $\mathrm{pg} / \mathrm{mL}, P=0.01$ ) when Acinetobacter baumannii infection developed. Multivariate logistic analysis indicated that high serum level of $\mathrm{Cr}(\mathrm{RR}, 0.934,95 \% \mathrm{Cl}, 0.890-0.981 ; P=0.007)$ and high BUN/ALB level (RR, 107.893, 95\%Cl, $1.425-$ 870.574; $p=0.005$ ) were associated with high risk of mortality in MDR/XDR Acinetobacter baumannii infected patients.

Conclusion: MDR/XDR Acinetobacter baumannii infection is a serious concern in pediatric patients with high mortality. Bloodstream and central nervous system infection accounted for high risk of death. Acute kidney injury is associated with high risk of mortality.
\end{abstract}

Keywords: MDR/XDR, Acinetobacter baumannii, Risk factors, Mortality, Pediatric intensive care units

\section{Background}

Acinetobacter baumannii is a Gram-negative coccobacillus that has a remarkable ability to acquire antibiotic resistance and that cause persistent nosocomial infections [1] The mortality rate varies from 18.26 to $88.7 \%$ depending on the infection source [2,3]. The propensity of Acinetobacter baumannii to be multidrug-resistant (MDR) or extensively drug-resistant (XDR) presents therapeutic challenges $[4,5]$. Invasive operations such as endotracheal mechanical ventilation, inserted invasive devices, intensive care unit stay, recent surgery, use of broad-spectrum antibiotics, ineffective management, and septic shock at diagnosis are reported as risk factors for colonization or infection by MDR Acinetobacter baumannii and higher mortality [6, 7].

The incidence of infections due to MDR Acinetobacter baumannii in Southeast Asia were higher compared to other areas $[8,9]$, According to a five-year case-control study from Southwest China, it was the severity of illness (high APACHE II score and MODS) that highlighted the mortality of patients with nosocomial Acinetobacter baumannii bacteremia [10]. The problems for pediatrician in China are polymyxins cannot be obtained, tigecycline only became available in late 2016, and had limited experience in manage these young patients $[11,12]$.

In pediatric critically ill patients, underlying diseases, immune deficiency, and invasive operations all contributed to the higher incidence of multidrug resistant Acinetobacter baumannii infection [13]. Multidrug resistant Acinetobacter baumannii infection is responsible for a high mortality rate among neonates in the NICU [14]. According to a report from Seoul National University Children's Hospital, carbapenem nonsusceptibility, neutropenia, and prolonged ICU stay as independent risk factors for mortality due to Acinetobacter baumannii bacteremia in PICU patients [15]. However, no study has examined these risk factors for mortality or clinical features due to MDR/XDR Acinetobacter baumannii infection in critically ill pediatric patients in China. Thus, the objective of this study was to assess the outcome and risk factor in hospitalized children with multidrug resistant and extensively drug resistant Acinetobacter baumannii infection in a pediatric intensive care unit.

\section{Methods}

This retrospective study included pediatric patients who developed multidrug resistant and extensively drug resistant Acinetobacter baumannii infection in the pediatric intensive care unit (PICU) of Shanghai Children's Hospital in China from December 2014 to May 2018. Colonization was defined as positive culture results from clinical isolated samples (sputum and urethral catheter tips) without clinical manifestation of infection.

Acinetobacter baumannii clinical isolates were recovered from different specimens including blood, sputum, bronchoalveolar lavage fluid, cerebrospinal fluid, ascites, hydrothorax, wound swabs, and urine from immunocompromised pediatric patients with symptomatic clinical infections at least $48 \mathrm{~h}$ after PICU admission. Specimens collected from from different specimens were placed in $3 \mathrm{~mL}$ BHI broth and incubated at $37^{\circ} \mathrm{C}$ with constant rotation for $24 \mathrm{~h}$ and were then spread on MacConkey agar. An aliquot of $5 \mathrm{~mL}$ nutrient broth was homogenized added to agar, and incubated for $5 \mathrm{~min}$ at $22-25^{\circ} \mathrm{C}$. Then spread $100 \mu \mathrm{L}$ of sample on blood agar and incubated at $37^{\circ} \mathrm{C}$ for $24 \mathrm{~h}$. After that, a volume of $100 \mu \mathrm{L}$ saline peptone obtained from each floor sample was spread on blood agar and incubated at $37^{\circ} \mathrm{C}$ for $24 \mathrm{~h}$. Colonies were preliminarily screened by morphology and 
characterized by oxidase and triple sugar iron tests. The antibiotic susceptibility was determined using the disk diffusion method in our study. The following antimicrobial disks were used: ampicillin-sulbactam $(10 / 10 \mu \mathrm{g})$, ceftazidime $(30 \mu \mathrm{g})$, imipenem $(10 \mu \mathrm{g})$, gentamicin $(10 \mu \mathrm{g})$, cotrimoxazole $(1.25 / 23.75 \mu \mathrm{g})$, piperacillin $(100 \mu \mathrm{g})$ and cefepime $(30 \mu \mathrm{g})$. Susceptibility testing to the tested antibiotics was determined according to the Clinical and Laboratory Standards Institute (CLSI) interpretive criteria for disk diffusion method, as well as the broth dilution MIC measurement [16]. Serial two-fold dilutions ranging from 256 to $0.25 \mathrm{mg} / \mathrm{L}$ for ceftazidime, meropenem, and from 128 to $0.015 \mathrm{mg} / \mathrm{L}$ for tigecycline and colistin were prepared in fresh 96-well microtiter plates. The inoculum was prepared with a 6-h broth culture that gives a final concentration of $\sim 105 \mathrm{CFU} / \mathrm{ml}$ in the test tray. The inoculums were then incubated overnight $(16-18 \mathrm{~h})$ at $37^{\circ} \mathrm{C}$ without shaking. The MIC was defined as the lowest concentration of antibiotic giving complete inhibition of visible growth. MDR was defined as acquired non-susceptibility to at least one agent in three or more antimicrobial categories, XDR was defined as non-susceptibility to at least one agent in all but two or fewer antimicrobial categories (i.e. bacterial isolates remain susceptible to only one or two categories) and PDR (pandrug resistant) was defined as nonsusceptibility to all agents in all antimicrobial categories [17]. According to CLSI criteria, we defined infection as follow:1) Blood stream infection: Patient has fever and has a recognized pathogen cultured from 1 or more blood cultures and organism cultured from blood is not related to an infection at another site, or had hemodynamic instability.2) Ventilator associated pneumonia (VAP): Patients with new or progressive and persistent infiltrate in X-rays, with new onset of purulent sputum, change in the character of sputum, more suctioning requirements or worsening gas exchange.3) Central line-associated bloodstream infection: A central line-associated bloodstream infection was defined as a patient who had at least 1 of the following signs or symptoms: hypothermia or hyperthermia, apnea and positive laboratory results not related to an infection at another site that were central venous line-associated with the central venous catheter having been in place at the time of, or within $48 \mathrm{~h}$ before, the onset of bacteremia. 4) Meningitis: Meningitis was defined as a patient had organisms cultured from cerebrospinal fluid (CSF), as well as who had at least 2 of the following signs or symptoms with no other recognized cause: headache, dizziness, fever, localizing neurologic signs, changing level of consciousness, or confusion. 5) Intraabdominal infections: Intraabdominal infections must meet at least 1 of the following criteria: Patient had at least 2 of the following signs or symptoms with no other recognized cause: fever, nausea, vomiting, abdominal pain, or jaundice, and the patient had organisms cultured from purulent material from intraabdominal space obtained during a surgical operation or needle aspiration. 6) Urinary tract infection: Urinary tract infection was defined as patient had a positive urine culture, that is, $\geq 10^{5}$ microorganisms per cc of urine with no more than 2 species of microorganisms. At least 2 urine cultures with repeated isolation of the same uropathogen (gram negative bacteria or Staphylococcus saprophyticus) with $\geq 10^{2}$ colonies $/ \mathrm{mL}$ in nonvoided specimens. Tracheal aspirate specimens were qualified on a quantification $(\mathrm{cfu} / \mathrm{mL})$ from the culture, the colony quantification less than $1 \times 10^{3} \mathrm{cfu} / \mathrm{mL}$ was considered as possible colonization.

\section{Clinical conditions and outcomes}

Clinical, biological and treatment data were obtained retrospectively from the patients' medical records. Underlying illnesses at the time of admission to the PICU were classified and pediatric risk of mortality III (PRISM III) scores were measured at the time of PICU admission. Shock was defined according to FEAST study [18]. The overall mortality was defined as death occurring before discharge. The Acinetobacter baumannii-associated mortality was defined as death caused by Multidrug resistant and extensively drug resistant Acinetobacter baumannii infection but not other pathogen infection. The primary outcome was overall mortality. Secondary outcomes included the Acinetobacter baumannii-associated mortality and the length of hospital stay.

\section{Statistical analysis}

Continuous variables were presented as mean \pm standard deviation for normal distribution data and as median (interquartile range) for abnormal distribution data. Comparative analysis was conducted using an independent sample nonparametric test. The chi-square test or Fisher's exact test was conducted. The MannWhitney test was used for continuous variables. Variables showing $p<0.05$ in a univariate analysis were included in a multivariate analysis, which was performed by stepwise logistic regression. All statistical analyses were performed with the Statistical Package for the Social Sciences, version 17.0 (SPSS Inc., Chicago, IL, USA).

\section{Results}

\section{Clinical manifestations}

During the study period of December 1st 2014 and May 31st, 2018, a total of 102 episodes of MDR/XDR Acinetobacter baumannii in 102 patients were identified, their demographics and clinical features were summarized in Table 1. The overall incidence of MDR/XDR Acinetobacter baumannii was 0.48 cases/1000 patient-days, and we observed a continually increased distribution of cases during 
Table 1 The Basic Characteristics of MDR/XDR Acinetobacter baumannii patients

\begin{tabular}{|c|c|c|c|c|c|}
\hline \multicolumn{2}{|l|}{$\begin{array}{l}\text { Characteristics } \\
\mathrm{n}(\%)\end{array}$} & \multirow{2}{*}{$\begin{array}{l}\text { Survivors } \\
72(70.59) \\
30(9.6,88.75)\end{array}$} & \multirow{2}{*}{$\begin{array}{l}\text { Nonsurvivors } \\
30(29.41) \\
42(9.825,102.75)\end{array}$} & \multirow{2}{*}{$\begin{array}{l}\text { Odds Ratio } \\
(95 \% \text { Cl) } \\
0.691(-29.63,12.02)\end{array}$} & \multirow{2}{*}{$\frac{P \text { value }}{0.404}$} \\
\hline Age, mean $\pm S D$, month & & & & & \\
\hline Male/Female $(n=)$ & & $44 / 28$ & $19 / 11$ & $(0.286,0.478)$ & 0.835 \\
\hline \multirow[t]{9}{*}{ Underlying disorders } & Pneumonia n (\%) & $61(84.7)$ & $25(83.3)$ & $0.902(0.284,2.862)$ & 0.862 \\
\hline & Meningitis n (\%) & $1(1.38)$ & $6(20)$ & $17.75(2.033,154.993)$ & $<0.001^{*}$ \\
\hline & Leukemia/Solid tumor n (\%) & $6(8.33) / 10(13.89)$ & $6(20) / 11(33.3)$ & $4.577(1.84,51.383)$ & $<0.001$ \\
\hline & Trauma n (\%) & $3(4.17)$ & $0(0)$ & $0.557(0.547,0.567)$ & 0.553 \\
\hline & Sepsis n (\%) & $65(90.27)$ & $25(83.33)$ & $0.538(0.156,1.855)$ & 0.321 \\
\hline & Peritonitis n (\%) & $8(11.11)$ & $8(26.67)$ & $2.909(0.975,8.68)$ & 0.049 \\
\hline & Cardiovascular disease $\mathrm{n}(\%)$ & $8(11.11)$ & $5(16.67)$ & $1.35(0.401,0.454)$ & 0.627 \\
\hline & Hepatic disorder n (\%) & $5(6.94)$ & $2(6.67)$ & $0.814(0.149,4.462)$ & 0.813 \\
\hline & Others n (\%) & $10(13.89)$ & $5(16.67)$ & $1.24(0.385,3.994)$ & 0.718 \\
\hline WBC count $\left(* 10^{9} / \mathrm{L}\right)$ & $M(Q 1, Q 3)$ & $7.99(5.81,13.62)$ & $5.1(1.64,14.78)$ & & 0.046 \\
\hline Neutropenia(* $\left.{ }^{*} 10^{9} / \mathrm{L}\right)$ & $M(Q 1, Q 3)$ & $4.88(3.51,9.1)$ & $3.37(0.61,11.05)$ & & 0.158 \\
\hline CRP (mg/L) & $M(Q 1, Q 3)$ & $37(10,74)$ & $27(16,94.5)$ & & 0.406 \\
\hline PCT (ng/L) & $M(Q 1, Q 3)$ & $0.48(0.18,5.08)$ & $1.56(0.53,8.27)$ & & 0.066 \\
\hline Lactate (mmol/L) & mean $\pm S D$ & $3.12 \pm 2.9$ & $3.09 \pm 2.42$ & & 0.955 \\
\hline PRISM III & mean $\pm S D$ & $6.73 \pm 5.19$ & $8.3 \pm 4.76$ & & 0.183 \\
\hline Shock & n (\%) & $18,25 \%$ & $16,53.33 \%$ & $3.429(1.403,8.382)$ & $0.006^{*}$ \\
\hline $\mathrm{PaO}_{2} / \mathrm{FiO}_{2}$ & mean $\pm S D$ & $269 \pm 113.55$ & $220.96 \pm 150.16$ & & 0.139 \\
\hline \multicolumn{6}{|l|}{ Exposure factors } \\
\hline & Steroid n (\%) & 49 (68.06) & $21(70)$ & $1.619(0.662,3.963)$ & 0.289 \\
\hline & Immune suppressor n (\%) & $11(15.27)$ & $8(26.67)$ & $2.017(0.718,5.665)$ & 0.263 \\
\hline & Length of hospital day (day,M(Q1,Q3)) & $24(14,48.75)$ & $31.5(24.75,41.5)$ & & 0.605 \\
\hline & Length of PICU day (day,M(Q1,Q3)) & $14(8,23.5)$ & $22.5(13.25,41)$ & & 0.459 \\
\hline & $\begin{array}{l}\text { Length of broad-spectrum antibiotic } \\
\text { therapy (day,M(Q1,Q3)) }\end{array}$ & $22(12,43)$ & $31.5(24.75,41.5)$ & & 0.123 \\
\hline & $\begin{array}{l}\text { Length of mechanical ventilation } \\
\text { (day, M(Q1,Q3)) }\end{array}$ & $6(1,15)$ & $10(6,25)$ & & 0.02 \\
\hline & Length of CRRT/ECMO(h, M(Q1,Q3)) & $0(0,0)$ & $0(0,6)$ & & 0.02 \\
\hline & Central vein catheter $n(\%)$ & $69(95.83)$ & $30(100)$ & $1.435(1.26,1.634)$ & 0.256 \\
\hline & $\begin{array}{l}\text { Arterial catheter } \\
\mathrm{n}(\%)\end{array}$ & $58(80.56)$ & $29(96.67)$ & $7.0(0.877,55.872)$ & 0.036 \\
\hline & Intra trachea intubation $\mathrm{n}(\%)$ & $57(79.17)$ & $29(96.67)$ & $7.632(0.96,60.662)$ & 0.027 \\
\hline & Operation n (\%) & $31(43.06)$ & $20(66.67)$ & $2.645(1.085,6.448)$ & 0.03 \\
\hline
\end{tabular}

${ }^{*} p<0.01$

the study period. The overall mortality was defined as the survival status when the patient discharged. In our study, the overall mortality was $29.4 \%$ (30/102), while the Acinetobacter baumannii-associated mortality was $16.7 \%$ (17/102). In 28 cases $(27.5 \%)$ surveillance blood cultures became positive after clinical manifestation appeared, while 10 isolates from catheter $(9.8 \%)$ (6 central venous catheters, 2 PICCs, 1 venous infusion port and 1 arterial catheter), 4 cerebrospinal fluid (3.9\%) and 14(13.7\%) ascites and hydrothorax were identified MDR/XDR
Acinetobacter baumannii positive. 19 (18.6\%) samples from tracheal aspirate and 37 (36.3\%) from sputum cultures for MDR/XDR Acinetobacter baumannii positive. The median age was $36(9.6,98.8)$ months and male predominated (61.8\%). 51 patients had surgery $(50.0 \%)$ and 70 treated with corticosteroids (68.6\%), all these patients received broad-spectrum antibiotics treatment for more than one week (Fig. 1. Flowchart of patients with MDR/XDR Acinetobacter baumannii infection enrolled in this study.). 


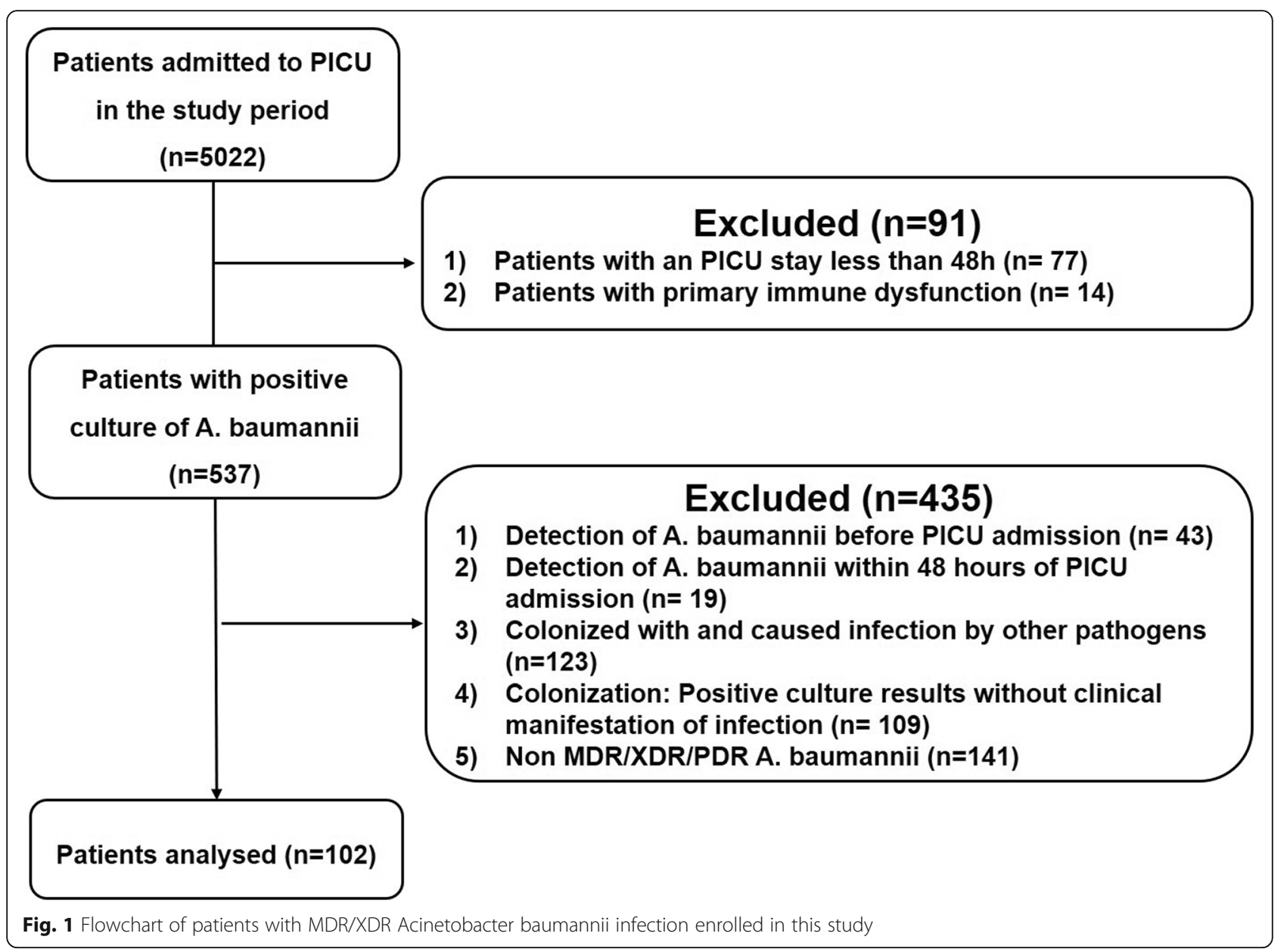

Organ function and immune status of MDR/XDR Acinetobacter baumannii infected patients

Table 2 listed the organ function of patients at diagnose of MDR/XDR Acinetobacter baumannii infection, as the concern of the importance of immunologic function in the process of anti-inflammatory pathophysiological, the indicators of immune function as well as serum cytokine levels were recorded in Table 3. It seems that no significant differences lies in the organ functions before they developed MDR/XDR Acinetobacter baumannii infection, but non-survival patients appeared to have a lower NK cell activity (6.2 \pm $3.61 \%$ vs. $9.15 \pm 6.21 \%, P=0.029)$, higher $C D 4^{+} \mathrm{T}$ cell ratio $(39.67 \pm 12.18 \%$ vs. $32.66 \pm 11.44 \%, P=0.039)$, at the same time, a higher serum level of interlukin- 8 (IL-8, $15.25(1.62,47.22) \mathrm{pg} / \mathrm{mL}$ vs. $0.1(0.1,22.99) \mathrm{pg} /$ $\mathrm{mL}, P=0.01)$ was noticed. The results from logistic regression showed that the risk factors for death among MDR/XDR Acinetobacter baumannii infection including high level of BUN/ALB and renal dysfunction (Table 4).
Drug resistance results of MDR/XDR Acinetobacter baumannii Bacteriological findings are summarized in Fig. 2. (Antimicrobial resistance in $102 \mathrm{~A}$. baumannii clinical isolates). MDR/XDR Acinetobacter baumannii was resistant to carbapenems, aminoglycosides, most cephalosporins and sulfa drugs. Their resistance rates were more than $75 \%$. Only tigecycline, polymyxin had a high sensitivity to MDR/XDR Acinetobacter baumannii (tigecycline sensitivity $89.87 \%$, polymyxin sensitivity $96.67 \%$ ). The resistance rate of cefoperazonesulbactam was $44 \%$ and its intermediate rate was $43 \%$.

\section{Outcomes}

A total of 102 patients with Acinetobacter baumannii infection were enrolled. All the patients received active antibiotic treatment within 7 days. Regarding treatment given within 7 days, based on the in vitro susceptibility test, cefoperazone/sulbactam, tigecycline, polymyxin were the recommended antimicrobial agents for XDR Acinetobacter baumannii eradication. The overall mortality rate was $29.4 \%$ (30/102), while the Acinetobacter baumannii-associated 
Table 2 Organ function of patients at diagnose of MDR/XDR Acinetobacter baumannii infection

\begin{tabular}{|c|c|c|c|}
\hline Organ & Survivors & Nonsurvivors & $P$ value \\
\hline \multicolumn{4}{|l|}{ Cardiovascular } \\
\hline $\mathrm{MAP}(\mathrm{mmHg})($ mean $\pm \mathrm{SD})$ & $64.02 \pm 12.99$ & $58.13 \pm 15.21$ & 0.052 \\
\hline $\mathrm{EF}(\%)($ mean $\pm \mathrm{SD})$ & $65.14 \pm 7.06$ & $66.78 \pm 3.09$ & 0.251 \\
\hline $\mathrm{Cl}(\mathrm{L} / \mathrm{min} \cdot \mathrm{m} 2)((\mathrm{M}(\mathrm{Q} 1, \mathrm{Q} 3))$ & $3.8(3.55,4.25)$ & $4(3,6.1)$ & 0.342 \\
\hline $\mathrm{LA}(\mathrm{mmol} / \mathrm{L})($ mean $\pm \mathrm{SD})$ & $3.12 \pm 2.9$ & $3.09 \pm 2.42$ & 0.955 \\
\hline \multicolumn{4}{|l|}{ Respiratory } \\
\hline $\mathrm{PEEP}\left(\mathrm{cmH}_{2} \mathrm{O}\right)($ mean $\pm \mathrm{SD})$ & $4.84 \pm 1.31$ & $6.24 \pm 2.02$ & $<0.001^{*}$ \\
\hline Tidal volume $(\mathrm{mL} / \mathrm{kg})($ mean $\pm \mathrm{SD})$ & $8.11 \pm 0.92$ & $7.98 \pm 0.83$ & 0.571 \\
\hline $\mathrm{PaO}_{2} / \mathrm{FiO}_{2}($ mean $\pm \mathrm{SD})$ & $269 \pm 112.76$ & $269 \pm 113.55$ & 0.084 \\
\hline Plateau pressure $\left(\mathrm{cmH}_{2} \mathrm{O}\right)((\mathrm{M}(\mathrm{Q} 1, \mathrm{Q} 3))$ & $10(9,12)$ & $11(10,13)$ & 0.684 \\
\hline \multicolumn{4}{|l|}{ Hepatic } \\
\hline TBIL(mmol/L) ((M(Q1,Q3)) & $6.26(4.14,9.76)$ & $10.86(6.64,18.85)$ & 0.443 \\
\hline $\operatorname{ALT}(\mathrm{U} / \mathrm{L})((\mathrm{M}(\mathrm{Q} 1, \mathrm{Q} 3))$ & $25.5(14,48)$ & $20(11.75,34.75)$ & 0.7 \\
\hline ALB(g/L) ((M(Q1,Q3)) & $33.68(30.95,37.35)$ & $31.88(27.96,34.65)$ & 0.027 \\
\hline \multicolumn{4}{|l|}{ Renal } \\
\hline $\mathrm{BUN}(\mathrm{mmol} / \mathrm{L})((\mathrm{M}(\mathrm{Q} 1, \mathrm{Q} 3))$ & $3.25(2.3,5.53)$ & $5.65(3.45,9.43)$ & $0.002^{*}$ \\
\hline $\operatorname{Cr}($ umol/L) ((M(Q1,Q3)) & $22(17,36.25)$ & $21(17.75,33.25)$ & 0.391 \\
\hline BUN/ALB & $0.17(0.09,0.27)$ & $0.09(0.06,0.16)$ & $0.001^{*}$ \\
\hline \multicolumn{4}{|l|}{ Nervous } \\
\hline Glasgow((M(Q1,Q3)) & $12(8.25,13)$ & $10.5(7,12)$ & 0.152 \\
\hline \multicolumn{4}{|l|}{ Gastric-intestine } \\
\hline Intra-abdominal pressure $\left(\mathrm{cmH}_{2} \mathrm{O}\right)($ mean $\pm \mathrm{SD})$ & $7.46 \pm 4.15$ & $8.95 \pm 5.01$ & 0.227 \\
\hline
\end{tabular}

mortality rate was $16.7 \%(17 / 102,12$ bloodstream infections, 4 meningitis and 1 intra-abdominal infection).

\section{Discussion}

Acinetobacter baumannii, an aerobic, gram-negative bacillus which is widely distributed in nature, is notorious

Table 3 The immunologic function and serum cytokines levels in the patients

\begin{tabular}{llll}
\hline Characteristics & Survivors & Nonsurvivors & $P$ value \\
\hline $\mathrm{NK}(\%)($ mean $\pm \mathrm{SD})$ & $9.15 \pm 6.21$ & $6.2 \pm 3.61$ & 0.029 \\
$\mathrm{lgG}(\mathrm{g} / \mathrm{L})($ mean $\pm \mathrm{SD})$ & $10.37 \pm 4.59$ & $10.56 \pm 4.84$ & 0.78 \\
$\mathrm{lgA}(\mathrm{g} / \mathrm{L})($ mean $\pm \mathrm{SD})$ & $1.01 \pm 0.92$ & $0.94 \pm 0.86$ & 0.77 \\
$\mathrm{lgM}(\mathrm{g} / \mathrm{L})($ mean $\pm \mathrm{SD})$ & $1.03 \pm 0.65$ & $0.66 \pm 0.45$ & 0.02 \\
$\mathrm{CD} 4^{+}(\%)($ mean $\pm \mathrm{SD})$ & $32.66 \pm 11.44$ & $39.67 \pm 12.18$ & 0.039 \\
$\mathrm{CD}{ }^{+}(\%)($ mean $\pm \mathrm{SD})$ & $28.72 \pm 13.83$ & $31.38 \pm 10.29$ & 0.43 \\
$\mathrm{CD} 19^{+}(\%)(\mathrm{mean} \pm \mathrm{SD})$ & $31.38 \pm 10.29$ & $23.74 \pm 17.18$ & 0.17 \\
$\mathrm{IL}-6(\mathrm{pg} / \mathrm{mL})(\mathrm{M}(\mathrm{Q} 1, \mathrm{Q} 3))$ & $0.1(0.1,22.25)$ & $323.86(0.1,733.62)$ & 0.14 \\
$\mathrm{IL}-8(\mathrm{pg} / \mathrm{mL})(\mathrm{M}(\mathrm{Q} 1, \mathrm{Q} 3))$ & $0.1(0.1,22.99)$ & $15.25(1.62,47.22)$ & $0.01^{*}$ \\
$\mathrm{IL}-10(\mathrm{pg} / \mathrm{mL})(\mathrm{M}(\mathrm{Q} 1, \mathrm{Q} 3))$ & $6.05(0.1,21.81)$ & $16.13(0.1,55.07)$ & 0.22 \\
\hline${ }^{*} \mathrm{p}<0.01$ & & &
\end{tabular}

for its remarkable Ability to acquire antibiotic resistance. As a result, it causes persistent hospital-acquired infections [1]. In our present study, the incidence density of MDR/XDR-Acinetobacter baumannii at our facility was 0.48 cases/1000 patient-days, which approximated to the incidence of 0.47 cases/1000 patient-days from reported in ICU patients [19] but lower than the incidence of another PICU that literature reports [2]. Patients in PICU always characterized by more severe underlying diseases, immune dysfunction and more complex medical history, all of these conditions will cause severe infection of Acinetobacter baumannii while MDR/XDR Acinetobacter baumannii strains appeared.

From our single-center data, ventilator-associated pneumonia (VAP) occupied the major complication in pediatric critically ill patients who MDR/XDR Acinetobacter baumannii infection with an incidence rate of

Table 4 Logistic regression of risk factors

\begin{tabular}{lll}
\hline variable & OR $(95 \% \mathrm{Cl})$ & P value \\
\hline BUN/ALB & $107.893(1.425-870.574)$ & $0.005^{*}$ \\
$\mathrm{Cr}(\mathrm{mmol} / \mathrm{L})$ & $0.934(0.890-0.981)$ & $0.007^{*}$ \\
\hline
\end{tabular}




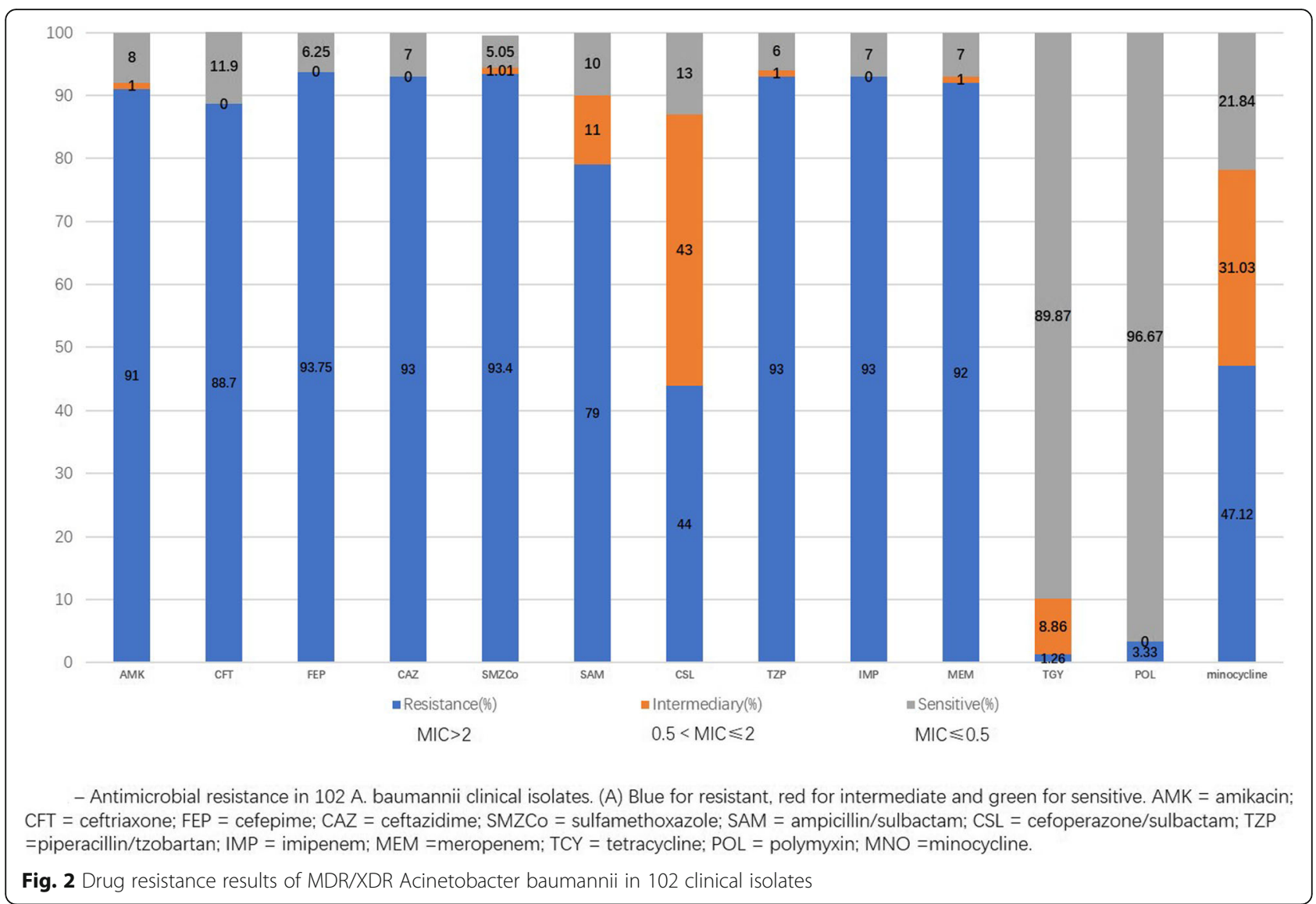

54.9\% (56/102). Both blood stream and CNS infection caused relative high mortality, in our research, 12 in 28 bloodstream infection patients and all 4 meningitis patients died. Due to increased invasive operations as well as the severity of primary conditions of critically ill patients, the overall incidence of MDR/XDR Acinetobacter baumannii infection increased.

MDR/XDR Acinetobacter baumannii is resistant to most pediatric antimicrobial agents, including penicillins, most cephalosporins, carbapenems, aminoglycosides, and sulfa drugs. XDR Acinetobacter baumannii tends to develop resistance to multiple antimicrobial agents through degrading enzymes targeting $\beta$ - lactams, increasing the expression of Ampc enzyme, modifying enzymes targeting aminoglycosides and alteration to the binding sites for quinolones, producing OXA-23 carbapenem enzyme, decreasing the expression of outer membrane pore channel protein, efflux pump system hyperactivity, and loss of PBPs. Additionally, MDR/XDR Acinetobacter baumannii could induce drug resistance through plasmid integration, while causing multiple drug resistance plasmids [20,21]. In our study, the susceptibility results showed that the drug resistance rates of MDR/XDR Acinetobacter baumannii to beta-lactam antibiotics were more than $75 \%$ except for cefoperazone/sulbactam (42\%). When it came to the in vitro activities of beta-lactamase inhibitors, sulbactam was superior to clavulanic acid and tazobactam. Sulbactam has good intrinsic antimicrobial activity against multidrug-resistant acinetobacter strains at concentrations readily achievable in human serum [22]. As the contribution of sulbactam, another antibiotic contains sulbactamampicillin/sulbatan, showed lower drug resistance rate (79\%) than other beta-lactam antibiotics. During the period of neither tigecycline nor polymyxin was available, a combination therapy of cefoperazone/sulbactam or fosfomycin and carbapenems was applied.

Since the safety of children's medication has been put in an important place, our choice of antibiotics faced a lot of limitations. Although no evidence in the literature that combination therapy is prior to single drug for infection with MDR/XDR Acinetobacter baumannii, some in vitro studies have shown that certain drug combinations are synergistic $[23,24]$. In the study by SingkhamIn $\mathrm{U}$ et al [25], the combination of $1 \times$ MIC of imipenem $(16-64 \mathrm{mg} / \mathrm{L}$, and $128 \mathrm{mg} / \mathrm{L}$ of isolate A10) and $1 \times$ MIC of fosfomycin (128-256 mg/L) showed synergism and bactericidal effect against most Acinetobacter baumannii isolates. Fosfomycin, when combined with imipenem, may enhance the inhibition of bacterial cell wall synthesis. So, from this point of view, the combination of 
fosfomycin and carbapenems in the past few years benefited a number of our patients.

Acinetobacter baumannii was transported together by infiltrating neutrophils. Go Kamoshida et al. [26] found that Acinetobacter baumannii exploits human neutrophils by adhering to and inducing IL-8 release for bacterial portage. Acinetobacter baumannii stimulation IL-8 plays a critical role in enhancing the migration of Acinetobacter baumannii -adhering neutrophils, the migration of Acinetobacter baumannii was suppressed when the infiltration of neutrophils was suppressed by inhibiting IL-8 [27]. Through Toll-like receptor 4 (TLR4) and CD14, Acinetobacter baumannii lipopolysaccharide leads the production of the neutrophil chemotactic factor IL-8 and the proinflammatory cytokine TNF- $\alpha$ [28]. In our MDR/XDR Acinetobacter baumannii infected patients, a higher serum level of IL-8 $(15.25(1.62,47.215) \mathrm{pg} / \mathrm{mL}$ vs. $0.1(0.1,22.99) \mathrm{pg} / \mathrm{mL})$ was detected in the non-survival group, this phenomenon might explain that Acinetobacter baumannii in this group seems to spread throughout the body more easily.

Studies have shown that purified TLR2 ligands from Acinetobacter baumannii are immunostimulatory [29]. $\mathrm{CD}_{4}{ }^{+} \mathrm{T}$ cells play important role in the Th1/Th2 paradigm, participate in inflammation [30], AbOmpA of Acinetobacter baumannii (AbOmpA) is a major porin protein in the outer membrane and is partly responsible for apoptosis of eukaryotic cells. Jun SikLee et al [31] co-cultured CD4+ splenic T cells with AbOmpA-treated DCs, and found AbOmpA directs $\mathrm{CD}_{4}{ }^{+} \mathrm{T}$ cell differentiation towards a Th1 response. Most biofilms provide a mechanical barrier to phagocytosis much like a capsule. A small number of bacteria become biologically active by migration from the biofilm or by shearing forces that remove small clumps of the biofilm. These bacteria released from the biofilm can induce not only host responses but also act as the seeding colony for the establishment of another infectious focus [32]. In our research, the patients in non-survival group appeared a higher $\mathrm{CD}^{+} \mathrm{T}$ cell ratio than survival patients, which revealed that a persistent neutrophil activation and accumulation in tissue that caused inflammation spread.

Critically ill patients had increased oxygen consumption, when these patients accompanied with capillary leak syndrome, they often had hydration status resulting in increasing reabsorption of urea by the kidneys, and reduction of ALB, elevation of BUN level can be frequently observed. Current studies highlighted BUN/ALB level as a predictor of 30-day mortality in a large sample of adult patients with hospital acquired pneumonia [33], and in our research, we also find that high BUN/ALB level associate with worse clinical outcome $(0.09(0.06$, $0.16)$ vs. $0.17(0.09,0.27), p=0.001)$, which coincide with the results in adult patients.
Our study had several limitations. First, because data were collected retrospectively from medical records, some parameters had to be inferred from the charts. Susceptibility testing had limitations, fosfomycin was not included, which resulted in a lack of antibiotic susceptibility evidence when we made treatment decisions.

In conclusion, our study suggests that MDR/XDRAcinetobacter baumannii is an important opportunistic pathogen that causes nosocomial infection in PICU with a rather high mortality. The incidence increased these years. Bloodstream and central nervous infection accounted for high risk of death. Increased invasive operations, IL- 8 releasing, and persistent neutrophil activation contributed to the risk of death.

\section{Conclusion}

MDR/XDR Acinetobacter baumannii infection is a serious concern in pediatric patients with high mortality. Bloodstream and central nervous system infection accounted for high risk of death. Acute kidney injury is associated with high risk of mortality.

\section{Abbreviations \\ MDR: Multidrug resistant; XDR: Extensively drug resistant; PDR: Pandrug resistant; PICU: Pediatric intensive care unit; CSF: Cerebrospinal fluid; CLSI: Clinical and Laboratory Standards Institute; PRISM III: Pediatric risk of mortality III; AKI: Acute kidney injury; ALT: Alanine transaminase; Cl: Cardiac index; BUN: Blood urea nitrogen; Cr: Creatinine; VAP: Ventilator-associated pneumonia; CRRT: Continuous renal replacement therapy; ECMO: Extracorporeal membrane; Lac: Lactate; EF: Left ventricular ejection fraction; $\mathrm{PaO}_{2} / \mathrm{FiO}_{2}$ : The ratio of the partial pressure of oxygen in arterial blood ( $\mathrm{PaO} 2)$ to the inspired oxygen fraction (FiO2)}

\section{Acknowledgements}

Not applicable.

\section{Authors' contributions}

YCZ and YJS designed the study. JYS, TS managed data and its quality. JYS, YJS and CXW performed the statistical analysis. FW, YPZ and HJM participated in the data interpretation. JYS, TS, YC drafted the manuscript. CXW and YCZ contributed substantially to its revision. All authors read the manuscript carefully and approved the final version.

\section{Funding}

This study was supported by the Multicenter Clinical Research Program of Shanghai Jiao Tong University School of Medicine (DLY201618), funded by the Science and Technology Commission of Shanghai Municipality (18411951000), supported by Shanghai Children's Hospital (2018YQN004). The funders had no role in the study design, data collection or analysis, decision to publish, or preparation of the manuscript.

\section{Availability of data and materials}

Our present study was a retrospective observational study. All the data were obtained from medical records of patients. The datasets used and/or analysed during the current study are available from the corresponding author on reasonable request, but the identifying/confidential patient data would not be shared.

\section{Ethics approval and consent to participate}

This study was approved by Ethics Review Committee, Children's Hospital of Shanghai/Shanghai Children's Hospital, Shanghai Jiao Tong University and conducted in accordance with the provisions of the Declaration of Helsinki (Approval No.2016R011-F01). The data used in our study was anonymized before its use. All the data were obtained from the medical records of 
patients. All data generated or analyzed during this study are available from the corresponding author upon reasonable request.

\section{Consent for publication}

Not applicable.

\section{Competing interests}

The authors have declared that no competing interests exist.

\section{Author details}

'Department of Critical Care Medicine, Shanghai Children's Hospital, Shanghai Jiao Tong University, Shanghai 20062, China. ${ }^{2}$ Institute of Pediatric Critical Care, Shanghai Jiao Tong University, Shanghai 20062, China. ${ }^{3}$ Department of Critical Care Medicine, Shanghai, Children's Hospital, Shanghai Jiao Tong University, No.355 Luding Road, Putuo District, Shanghai 200062, China.

Received: 18 December 2019 Accepted: 3 August 2020

Published online: 12 August 2020

\section{References}

1. Kempf M, Rolain JM. Emergence of resistance to carbapenems in Acinetobacter baumannii in Europe: clinical impact and therapeutic options. Int J Antimicrob Agents. 2012;39(2):105-14.

2. Cai XF, Sun JM, Bao LS, et al. Risk factors and antibiotic resistance of pneumonia caused by multidrug resistant Acinetobacter baumannii in pediatric intensive care unit. World J Emerg Med. 2012;3:202-7.

3. Nutman A, Glick R, Temkin E, et al. A case-control study to identify predictors of 14-day mortality following carbapenem-resistant Acinetobacter baumannii bacteraemia. Clin Microbiol Infect. 2014 Dec;20(12):01028-34.

4. Karlowsky JA, Hoban DJ, Hackel MA, et al. Antimicrobial susceptibility of gram-negative ESKAPE pathogens isolated from hospitalized patients with intra-ABdominal and urinary tract infections in Asia-Pacific countries: SMART 2013-2015. J Med Microbiol. 2017 Jan;66(1):61-9.

5. Hackel MA, Badal RE, Bouchillon SK, et al. Resistance rates of intraABdominal isolates from intensive care units and non-intensive care units in the United States: the study for monitoring antimicrobial resistance trends 2010-2012. Surg Infect. 2015 Jun;16(3):298-304.

6. Yamada K, Yanagihara K, Araki N, et al. Clinical characteristics of tertiary hospital patients from whom Acinetobacter calcoaceticus-Acinetobacter baumannii Complex strains were isolated. Intern Med. 2012:51(1):51-7.

7. Freire MP, de Oliveira GD, Garcia CP, et al. Bloodstream infection caused by extensively drug-resistant Acinetobacter baumannii in cancer patients: high mortality associated with delayed treatment rather than with the degree of neutropenia. Clin Microbiol Infect. 2016 Apr;22(4):352-8.

8. Teerawattanapong $\mathrm{N}$, Panich $\mathrm{P}$, Kulpokin $\mathrm{D}$, et al. A systematic review of the burden of multidrug-resistant healthcare-associated infections among intensive care unit patients in Southeast Asia: the rise of multidrug-resistant Acinetobacter baumannii. Infect Control Hosp Epidemiol. 2018 May;39(5): 525-33.

9. Ayobami $\mathrm{O}$. Willrich $\mathrm{N} 1$, harder $\mathrm{T}$, et al. the incidence and prevalence of hospital-acquired (carbapenem-resistant) Acinetobacter baumannii in Europe, eastern Mediterranean and Africa: a systematic review and metaanalysis. Emerg Microbes Infect. 2019;8(1):1747-59.

10. Yang S, Sun J, Wu X, et al. Determinants of mortality in patients with nosocomial Acinetobacter baumannii bacteremia in Southwest China: a five-year case-control study. Can J Infect Dis Med Microbiol. 2018 Jun 3; 2018:3150965.

11. Purdy J, Jouve $S$, Yan $J$, et al. Pharmacokinetics and safety profile of tigecycline in children aged 8 to 11 years with selected serious infections: a multicenter, open-IABel, ascending-dose study. Clin Ther. 2012 Feb;34(2): 496-507.e1.

12. Kanik-Yuksek S, Tezer H, Ozkaya-Parlakay A, et al. Multidrug-resistant Acinetobacter baumannii bacteremia treated with tigecycline in two pediatric burn patients. Pediatr Infect Dis J. 2015 Jun;34(6):677.

13. Kim B, Kim K, Yoon JS. Nosocomial Acinetobacter baumannii infection in children in adult versus pediatric intensive care units. Pediatr Int. 2020 Apr; 62(4):451-8.

14. Wei HM, Hsu YL, Lin HC, et al. Multidrug-resistant Acinetobacter baumannii infection among neonates in a neonatal intensive care unit at a medical center in Central Taiwan. J Microbiol Immunol Infect. 2015 Oct;48(5):531-9.
15. Choe YJ, Lee HJ, Choi EH. Risk factors for mortality in children with Acinetobacter baumannii bacteremia in South Korea: the role of Carbapenem resistance. Microb Drug Resist. 2019 Oct;25(8):1210-8.

16. Horan TC, Andrus M, Dudeck MA. CDC/NHSN surveillance definition of health care-associated infection and criteria for specific types of infections in the acute care setting. Am J Infect Control. 2008 Jun;36(5):309-32.

17. Magiorakos AP, Srinivasan A, Carey RB, et al. Multidrug-resistant, extensively drug-resistant and pandrug-resistant bacteria: an international expert proposal for interim standard definitions for acquired resistance. Clin Microbiol Infect. 2012 Mar;18(3):268-81.

18. Houston KA, George EC, Maitland K. Implications for paediatric shock management in resource-limited settings: a perspective from the FEAST trial. Crit Care. 2018;22(1):119.

19. Rossi I, Royer S, Ferreira ML, et al. Incidence of infections caused by carbapenem-resistant Acinetobacter baumannii. Am J Infect Control. 2019 Dec;47(12):1431-5

20. McConnell MJ, Actis L, Pachon J. Acinetobacter baumannii: human infections, factors contributing to pathogenesis and animal models. FEMS Microbiol Rev. 2013 Mar;37(2):130-55.

21. Peleg AY, Seifert H, Paterson DL. Acinetobacter baumannii: emergence of a successful pathogen. Clin Microbiol Rev. 2008;21:538-82.

22. Higgins $P G$, Wisplinghoff $H$, Stefanik $D$. In vitro activities of the betalactamase inhibitors clavulanic acid, sulbactam, and tazobactam alone or in combination with beta-lactams against epidemiologically characterized multidrug-resistant Acinetobacter baumannii strains. Antimicrob Agents Chemother. 2004:48:1586-92.

23. Zusman O, Avni T, Leibovici L, et al. Systematic review and meta-analysis of in vitro synergy of polymyxins and carbapenems. Antimicrob Agents Chemother. 2013;57:5104-11.

24. Ni W, Shao X, Di X, et al. In vitro synergy of polymyxins with other antibiotics for Acinetobacter baumannii: a systematic review and metaanalysis. Int J Antimicrob Agents. 2015 Jan;45(1):8-18.

25. Singkham-In U, Chatsuwan T. Singkham-In U. In vitro activities of carbapenems in combination with amikacin, colistin, or fosfomycin against carbapenem-resistant Acinetobacter baumannii clinical isolates. Diagn Microbiol Infect Dis 2018;91:169-174.

26. Kamoshida G, Tansho-Nagakawa S, Kikuchi-Ueda T, et al. A novel bacterial transport mechanism of Acinetobacter baumannii via activated human neutrophils through interleukin-8. J Leukoc Biol. 2016 Dec;100(6):1405-12.

27. Kolaczkowska E, Kubes P. Neutrophil recruitment and function in health and inflammation. Nat Rev Immunol. 2013 Mar;13(3):159-75.

28. Knapp S, Wieland CW, Florquin S, Pantophlet R, Dijkshoorn L, Tshimbalanga N, et al. Differential roles of CD14 and toll-like receptors 4 and 2 in murine Acinetobacter pneumonia. Am J Respir Crit Care Med. 2006 Jan 1;173(1):122-9.

29. March C, Regueiro V, Llobet E, et al. Dissection of host cell signal transduction during Acinetobacter baumannii-triggered inflammatory response. PLoS One. 2010 Apr 7;5(4):e10033.

30. Harrington LE, Hatton RD, Mangan PR, et al. Interleukin 17-producing CD4(+ ) effector T cells develop via a lineage distinct from the T helper type 1 and 2 lineages. Nat Immunol. 2005 Nov;6(11):1123-32.

31. Lee JS, Lee JC, Lee CM, et al. Outer membrane protein a of Acinetobacter baumannii induces differentiation of CD4+ T cells toward a Th1 polarizing phenotype through the activation of dendritic cells. Biochem Pharmacol. 2007 Jun 30;74(1):86-97.

32. KAJr M, Smith JW, Gamelli RL, et al. New perspectives for a new century: implications of pathogen responses for the future of antimicrobial therapy. J Burn Care Res. 2006 May-Jun;27(3):251-64.

33. Feng DY, Zhou YQ, Zou XL, et al. Elevated blood urea nitrogen-to-serum albumin ratio as a factor that negatively affects the mortality of patients with hospital-acquired pneumonia. Can J Infect Dis Med Microbiol. 2019; 2019:1547405

\section{Publisher's Note}

Springer Nature remains neutral with regard to jurisdictional claims in published maps and institutional affiliations. 